\title{
Stringer Bending Test Helps Diagnose and Prevent Cracks in the Space Shuttle's External Tank
}

\author{
Joseph B. Saxon ${ }^{1}$, Gregory R. Swanson ${ }^{2}$, William P. Ondocsin ${ }^{3}$, and Robert J. Wingate \\ NASA Marshall Space Flight Center, Huntsville, AL \\ Extended Abstract of Proposed Paper for the $53^{\text {rd }}$ AIAA/ASME/ASCE/AHS/ASC Structures, \\ Structural Dynamics, and Materials Conference, \\ April 23-26, 2012, Honolulu, Hawaii
}

Category: Structures

\section{INTRODUCTION}

Space Shuttle Discovery's last mission, STS-133, was scheduled to launch on November 5, 2010. Just hours before liftoff, a hydrogen leak at an umbilical connection scrubbed the launch attempt. After the scrub, further inspection revealed a large crack in the foam insulation covering the External Tank, ET-137. Video replay of the launch attempt confirmed the crack first appeared as cryogenic propellants were being loaded into the ET. When the cracked foam was removed, technicians found the underlying stringer had two 9-inch-long cracks. Further inspection revealed a total of 5 of the 108 ET stringers had cracked. NASA and Lockheed Martin immediately launched an aggressive campaign to understand the cracks and repair the stringers in ET-137, targeting February 2011 as the new launch date for STS-133.

Responsibilities for the various aspects of the investigation were widely distributed among NASA centers and organizations. This paper will focus on lab testing at Marshall Space Flight Center (MSFC) in Huntsville, Alabama that was intended to replicate the stringer failure and gauge the effect of proposed countermeasures.

\section{BACKGROUND}

The ET's function is to carry the cryogenic propellants that feed the three Space Shuttle main engines. The ET also receives and distributes thrust from the Solid Rocket Boosters (SRBs). On-going ET production allowed evolution of the design, and ET-137 represented the latest "Super-Lightweight" configuration, which made extensive use of Aluminum-Lithium alloys. Figure 1 shows the layout of the Super-Lightweight ET. The Intertank connects the liquid hydrogen (LH2) tank on the aft end and the liquid oxygen (LOX) tank on the forward end. Unlike the propellant tanks, the Intertank is not stiffened by internal pressure, so stringers are included to add stiffness and strength. These are the same stringers that cracked on ET-137 and are the focus of this investigation. The Intertank is constructed of eight panels, six of which are skin-stringer construction with a typical cross-section as shown in Figure 2. The stringers are mechanically attached to the skin with rivets along most of their length and with specialty fasteners, such as GP Lockbolts and Hi-Loks, at the forward and aft ends.

\footnotetext{
${ }^{1}$ Aerospace Engineer.

${ }^{2}$ MSFC Fracture Control Board Chairman.

${ }^{3}$ External Tank Test and Certification Team Lead.

${ }^{4}$ Aerospace Engineer and Team Lead, AIAA Member.
} 
When the propellants are loaded, both ends of the Intertank approach cryogenic temperature and contract inward. The center of the Intertank remains at warmer temperature and resists contraction, causing considerable bending of the stringers, especially at the ends. Figure 3 shows cracks on the LOX end of a stringer that are consistent with this loading scenario, appearing as if the stringer end pulled away from the skin, fracturing the stringer foot along the fastener line. Fractography analysis indicated the ET-137 fractures were static, initiating on the bottom of the stringer foot (the tensile side of bending) between the $2^{\text {nd }}$ and $3^{\text {rd }}$ fasteners from the end. The video footage of the launch attempt indicated that the fracture occurred precisely when the LOX level should have reached the Intertank/LOX tank interface. No cracks were detected at the LH2 end of the ET-137 Intertank.

\section{TEST DEVELOPMENT}

Early in the investigation, consensus developed for building a test fixture capable of bending stringers to the shape imposed by the cryogenically-induced bending of the Intertank. Initial tests would be at room temperature with the suitability of that limitation evaluated later. A typical test article is shown in Figure 4 and represents the forward 40 inches of the Intertank, including the flange chord that interfaces with the LOX tank. The fixture holds the aft end of the article stationary while pulling the forward end inboard, also limiting its rotation, achieving the target shape by bending the test article across contact surfaces located between the two ends. Some of the parallel efforts that influenced the test development are discussed next.

\section{$\underline{\text { Finite Element Analysis }}$}

Finite element analyses of a stringer subjected to prelaunch, launch, and flight conditions were performed. These analyses concluded that worst-case stringer stress occurred during the tanking transient rather than during flight. The finite element results for the tanking transient were confirmed by photogrammetry data collected during a tanking test. These finite element results and tanking test data helped define the target shape for the bending tests and confirmed that the bending test was representative of worst-case conditions.

\section{$\underline{\text { Pathfinder Test Articles }}$}

Significant lead time was required to obtain flight-like test articles. In the interim, initial bending tests were conducted using mock-up test articles designated as "pathfinders." The pathfinders were used to develop test procedures, check instrumentation, and experiment with mechanisms to control the deformed shape. In addition, the pathfinder tests highlighted the benefits of photogammetry techniques, which went on to play a key role in the test program. Overall, the pathfinder tests were very successful in helping develop the bending test, but none of the pathfinders trended toward the failures seen on ET-137.

\section{$\underline{\text { Material Findings }}$}

The team at the Michoud Assembly Facility (MAF) made a key observation that some stringers had a distinguishing "mottled" surface appearance. It was determined that many of the stringers on ET-137 exhibited this mottled appearance, including all of the stringers that cracked. 
Preliminary metallurgical tests hinted that mottled material might have out-of-family fracture behavior. Further investigation showed that all of the mottled stringers came from two specific heat lots, thus creating a category of "suspect" stringers. All stringers from those heat lots were considered suspect regardless of their appearance which varied in severity of mottling.

\section{$\underline{\text { Radius Block Installation }}$}

Based on early indications from the crack investigation, NASA management made the proactive decision to reinforce all of the stringers on ET-137 by installing so-called radius blocks. The radius block $(\mathrm{RB})$ placement is shown in Figure 5. Stringers with RB's became another configuration that required testing.

\section{"New Year's Eve" Test}

On December 31, 2011, MSFC tested its first flight-like stringer. There were two defining characteristics of this bending test: (1) the stringer was from a suspect heat lot, and (2) it marked the first use of the double-fulcra configuration shown in Figure 4. The double-fulcra was intended to drive more load into the forward fasteners than achieved in the pathfinder tests. The test reached an estimated nominal deflection without incident, but with a small and slow increase in load, the stringer failed suddenly with a fracture pattern that perfectly matched that seen on ET-137. This was a watershed moment since no previous testing at MSFC or MAF had clearly replicated the failures seen on ET-137.

The MSFC test plan subsequently developed around a population of stringers with three major variations: (1) whether the stringer came from a suspect or nominal heat lot, (2) the absence or presence of radius blocks, and (3) the number of skin doublers on the Intertank wall, which essentially equates to stringer location on the Intertank. The resulting test matrix is shown in Table 1 where the New Year's Eve test is designated S7-7. In the test matrix, twenty of the entries are based strictly on the three factors mentioned above. Two more entries address the "short-chord" configuration that occurs in a very few places on the LOX end of the Intertank, but is typical of the LH2 end.

\section{TESTING, OBSERVATIONS, AND RESULTS}

Between January 2 and February 5, 2011, MSFC tested to failure each article enumerated in the test matrix (see Table 1). Test data from strain gages, linear variable-differential transformers (LVDTs), and the load cell were tracked to identify emerging trends. Real time display of photogrammetry data was also used to monitor emerging strain patterns. Review of high-speed video was used to confirm where the cracks initiated. Failure was defined at the point of maximum load. Two key observations concerning typical stringer failure were noted:

- Stringers from suspect heat lots failed suddenly, with a loud pop, a sudden load drop, and long cracks initiating at the forward fasteners and propogating aft.

- Stringers from nominal heat lots failed gradually, with small incremental load drops up to the maximum load and cracks often initiating at the fulcra and propogating forward. 
The final crack patterns looked very similar for both populations. Failure surfaces were examined by fractography to confirm initiation location and failure progression. Coupons were cut from the failed stringers and tested for strength, elongation, and fracture toughness to aid understanding of the root cause material behavior.

Comparative results from the stringer bending tests are summarized in Figure 6, where each article's failure point is plotted in load-deflection space. Three observations are noted:

- Suspect stringers as a group sustained less bending load and/or deflection prior to failure than nominal stringers.

- Suspect stringers reinforced with radius blocks demonstrated improved bending capacity, on par with that of the nominal stringers.

- Nominal stringers reinforced with radius blocks suffered no detrimental effects to bending capacity.

In this paper, it will be shown that the MSFC stringer bend tests helped identify the root cause of the ET-137 stringer cracks, helped develop the flight rationale for ET-137 as modified with radius blocks, and supported the target launch date for STS-133 in Feb-2011.

\section{ACKNOWLEDGEMENTS}

The authors would like to gratefully acknowledge the engineers and technicians at the MSFC Materials and Environmental Test Complex (METCO) Hot Gas Facility for their contribution to constructing the test apparatus and performing the stringer tests. Also, special thanks to Mr. Todd Boles for his extensive oversight of the photogrammetry process and data. 


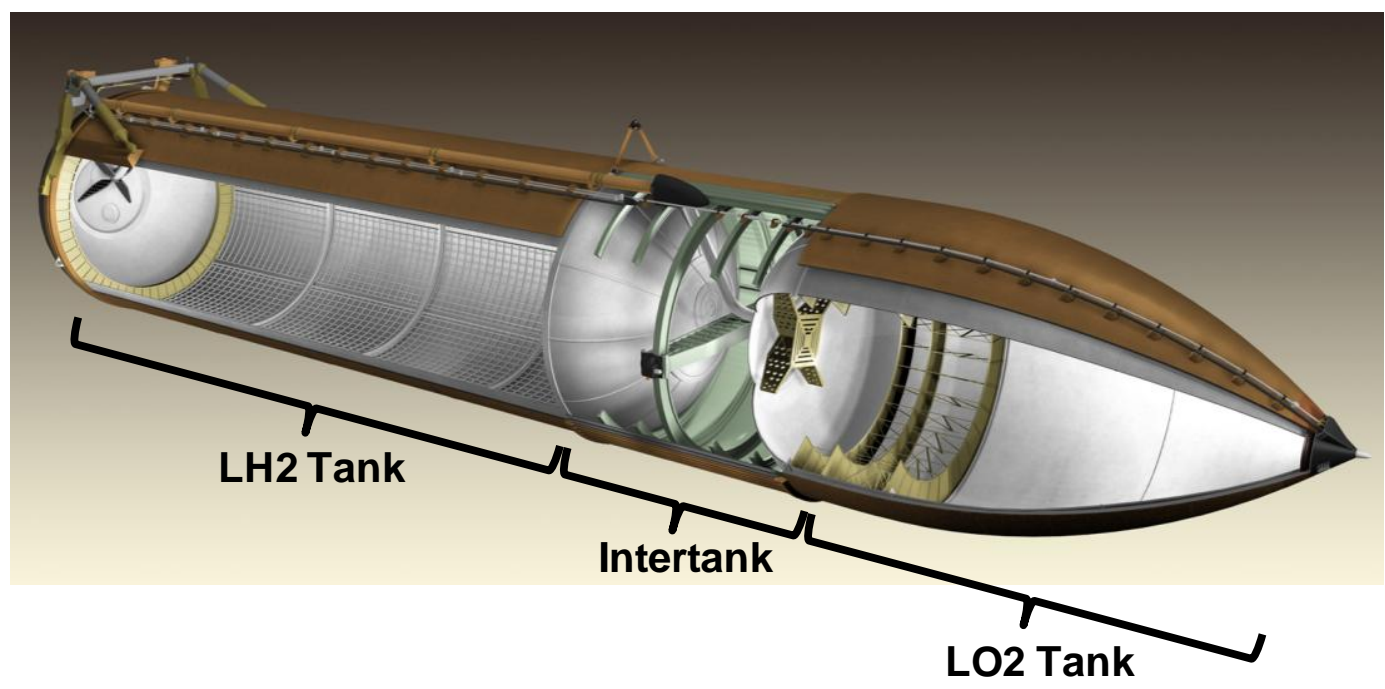

Figure 1. Super-lightweight external tank.

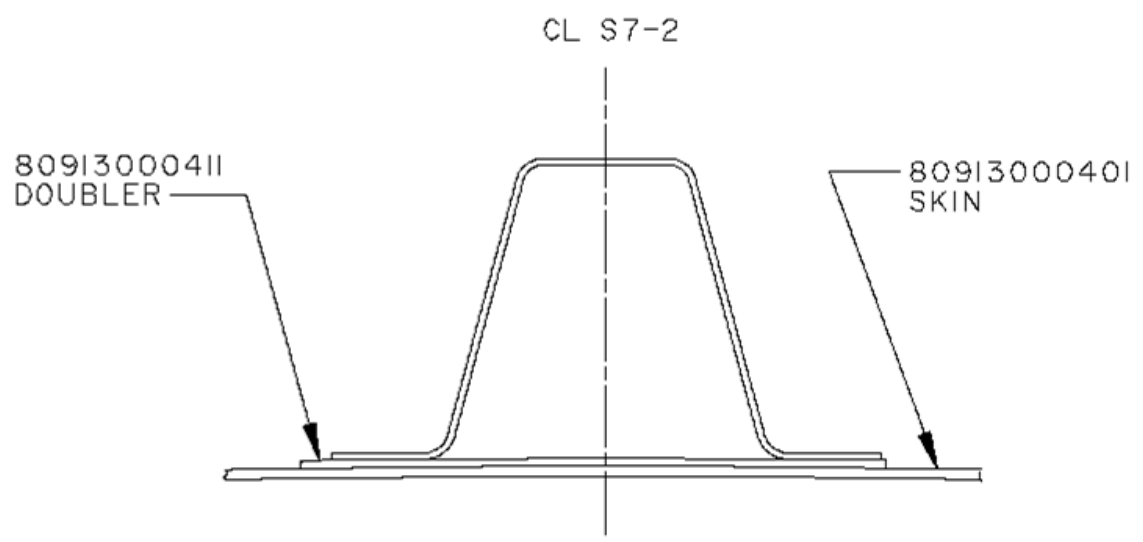

Figure 2. Typical Intertank skin and stringer cross section. 


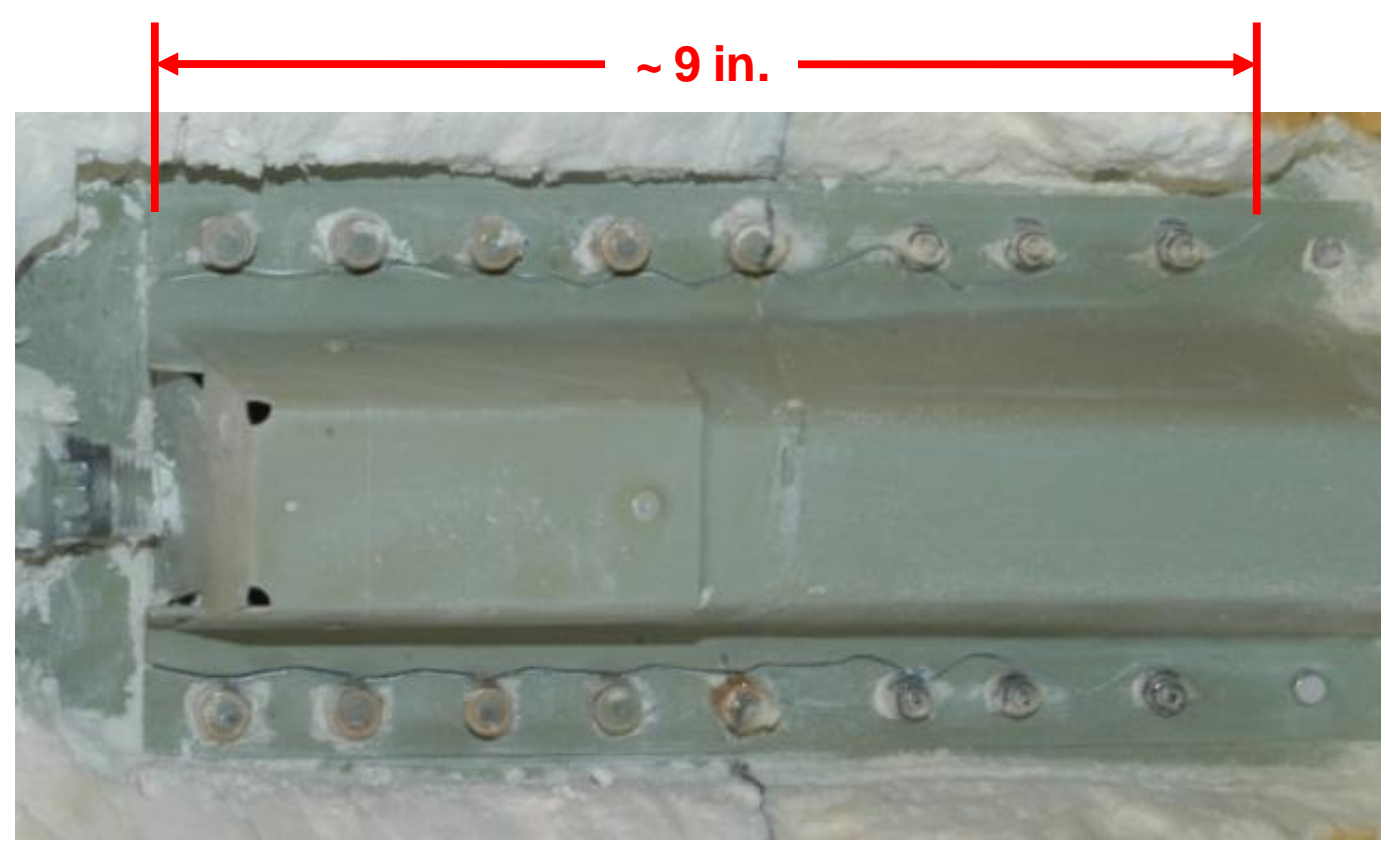

Figure 3. Cracks at LOX end of ET-137 stringer S7-2.

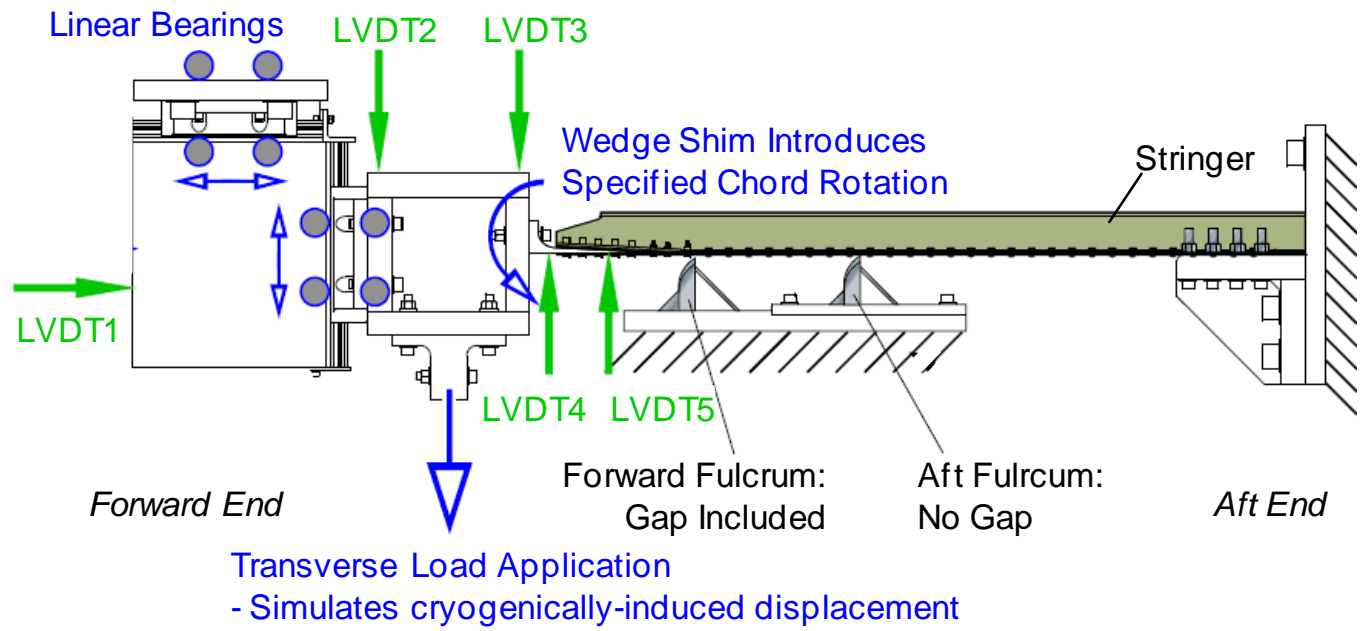

Figure 4. MSFC single stringer bending test configuration. 


\section{Radius Block}

Figure 5. Radius block for proactive stringer repair.

Table 1. MSFC test matrix.

\begin{tabular}{|c|c|c|c|c|c|c|c|c|c|}
\hline Doublers & Category & Test Date & Cycles & Configuration & $\begin{array}{c}\text { (ET-139) } \\
\text { Stringer- } \\
\text { Panel }\end{array}$ & \begin{tabular}{|l} 
LVDT3 at \\
Failure
\end{tabular} & $\begin{array}{l}\text { Load at } \\
\text { Failure }\end{array}$ & Failure Type & $\begin{array}{c}\text { Initial Failure } \\
\text { Location }\end{array}$ \\
\hline \multirow{10}{*}{0} & Nominal & $1 / 17 / 2011$ & 1 & Retrofit & S15-7.1 & 1.184 & 3266 & progressive & mandrel \\
\hline & Nominal & $1 / 22 / 2011$ & 1 & Retrofit & S16-7.1 & 1.092 & 3184 & progressive & mandrel \\
\hline & Nominal + RB & $1 / 29 / 2011$ & 1 & Retrofit & S15-7.2 & 1.092 & 3214 & progressive & mandrel \\
\hline & Suspect & $1 / 8 / 2011$ & 1 & Original build & S15-7 & 0.73 & 1966 & sudden & feet \\
\hline & Suspect & $1 / 9 / 2011$ & 1 & Original build & S16-7 & 0.681 & 1655 & sudden & feet \\
\hline & Suspect & $1 / 18 / 2011$ & 1 & Orginal/short chord & $56-8$ & 0.738 & 1641 & sudden & feet \\
\hline & Suspect & $1 / 19 / 2011$ & 1 & Original build & S14-7 & 0.73 & 1652 & sudden & feet \\
\hline & Suspect + RB & $1 / 20 / 2011$ & 1 & Retrofit/short chord & S8-8 & 1.01 & 2822 & sudden & mandrel \\
\hline & Suspect + RB & $1 / 15 / 2011$ & 1 & Original build & S11-7 & 0.932 & 2965 & sudden & feet \\
\hline & Suspect + RB & $1 / 14 / 2011$ & 13 & Original build & S17-7 & 0.971 & 2807 & sudden & feet \\
\hline \multirow{9}{*}{1} & Nominal & $1 / 9 / 2011$ & 1 & Original build & S9-7 & 0.863 & 2743 & progressive & feet \\
\hline & Nominal & $1 / 29 / 2011$ & 1 & Retrofit & S9-7.1 & 1.044 & 3547 & progressive & mandrel \\
\hline & Nominal + RB & $1 / 25 / 2011$ & 1 & Retrofit & S8-7.1 & 1.095 & 3637 & progressive & mandrel \\
\hline & Nominal + RB & $1 / 26 / 2011$ & 13 & Retrofit & S8-7.2 & 1.1 & 3486 & progressive & mandrel \\
\hline & Suspect & $12 / 31 / 10$ & 3 & Original build & S7-7 & 0.589 & 1539 & sudden & feet \\
\hline & Suspect & $1 / 17 / 2011$ & 1 & Retrofit & S7-7.1 & 0.874 & 2363 & sudden & feet \& hat \\
\hline & Suspect + RB & $1 / 15 / 2011$ & 1 & Original build & S8-7 & 1.201 & 3692 & progressive & mandrel \\
\hline & Suspect + RB & $1 / 23 / 2011$ & 13 & Retrofit & S7-7.2 & 1.031 & 3424 & sudden & feet \\
\hline & Suspect + RB & $1 / 30 / 2011$ & 1 & Retrofit & S9-7.2 & 1.023 & 3365 & sudden & feet \\
\hline \multirow{3}{*}{2} & Nominal & $1 / 9 / 2011$ & 1 & Original build & S2-7 & 0.823 & 2418 & progressive & feet \\
\hline & Suspect & $1 / 19 / 2011$ & 1 & Retrofit & $\mathrm{S} 2-7.1$ & 0.754091 & 2293 & sudden & feet \\
\hline & Suspect + RB & $1 / 24 / 2011$ & 1 & Retrofit & $\mathrm{S} 2-7.2$ & 0.940071 & 3067 & sudden & feet \\
\hline
\end{tabular}




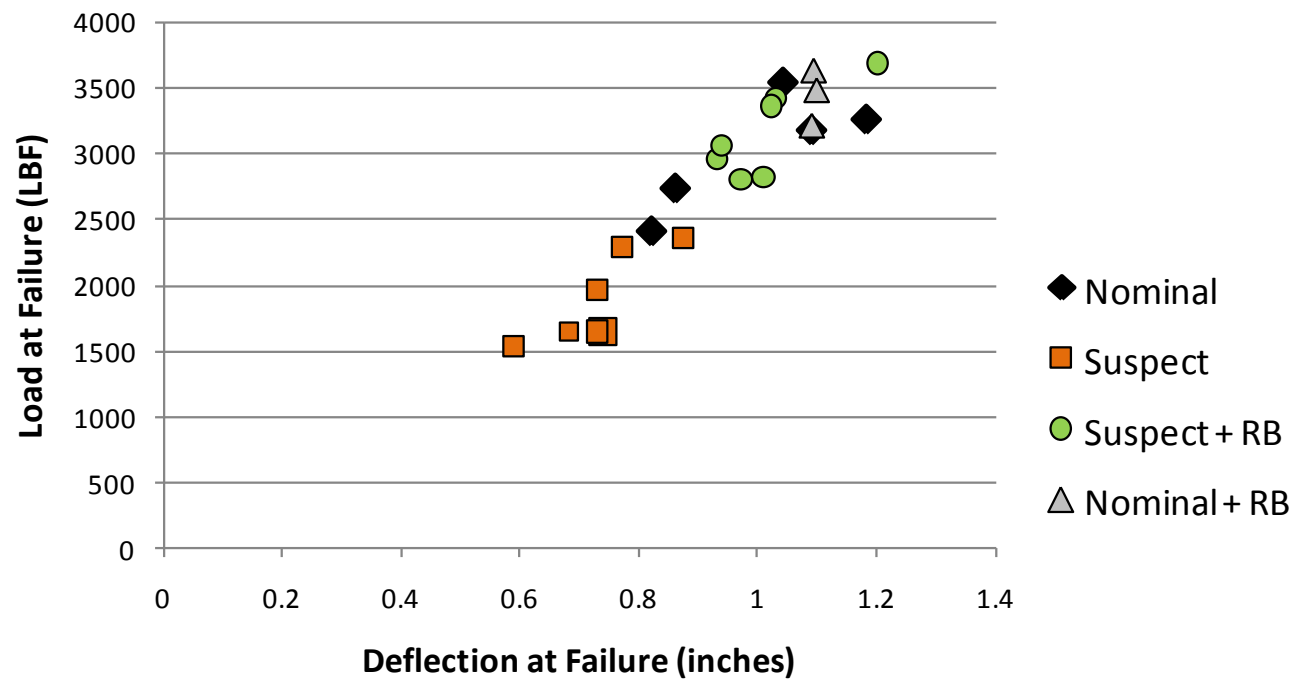

Figure 6. MSFC bending test results. 